\title{
Study of Score System for Surgical Difficulty of Laparoscopic Cholecystectomy
}

\author{
Chen-Guo Ker ${ }^{1 *}$, Hong-Yi Tong ${ }^{1}$, Ming-Yuen Yang ${ }^{1}$, I-Tsou Tseng ${ }^{1}$, Der-Ming Chang ${ }^{1}$, Kuo-Chen Hung ${ }^{1}$, \\ Hong-Yaw Chen ${ }^{1}$ and Yu-Fu Chen ${ }^{2}$
}

${ }^{1}$ Department of Digestive Surgery, Yuan's General Hospital, Kaohsiung, Taiwan

${ }^{2}$ Department of Medical Research and Education, Yuan's General Hospital, Kaohsiung, Taiwan

\begin{abstract}
Introduction: Grading scales for the surgical difficulty of laparoscopic cholecystectomy (LC) had been mentioned but not common. In order to clarify and compare grading score for the surgical difficulty of LC, we conducted this study to present our grading scoring method by measuring the time of laparoscopic cholecystectomy.

Patients and methods: There were 206 patients treated with LC under the diagnosis of acute cholecystitis based on the criteria of Tokyo Guideline 2013 (TG13). These 206 patients were 89 of male, and 117 of female and their age ranged 23-85 year-old. We designed a worksheet as Surgical Difficulty Scoring Scale of LC. Our scoring scale was based on the peri-operative findings of appearance of GB (0-3 score), Calot's triangle (0-3 score), GB bed (0-3 score) and additional 3 conditions (gangrene GB, GB fistula, and Mirizzi's symdrome, 0-3 score for each). Concerning the cholecystectomy time was defined and measured from the beginning with the laparoscopic instrument grasping GB to the end of GB separated and homeostasis completely. Surgical difficulty (SD) grading was classified in to SD Grade 1, 2, and 3 for the score 0-3. $4-12$, and $>14$ respectively.

Results: The distributions of SD Grading 1, 2 and 3 were found in 92 (50\%), 78 (32.5\%), and 32 (17.5\%) patients respectively. The cholecystectomy time was measured $23.9 \pm 11.5,41.5 \pm 23.6$ and $74.3 \pm 32.1$ min for SD Grade 1,2 , and 3 respectively with a significant difference $(p<0.001)$. The SD Grade 3 was found to have an elder age, male, and Grade $2 \& 3$ of acute cholecystitis. Multiple regression analysis for the predictor of surgical difficulty of LC showed that the SD Grade 2 and 3 had 1.77 and 4.5 times difficulty than that of SD Grade 1.

Conclusion: Either score system or grading system was approved to be a police of surgical treatment of LC for benign GB diseases. Severe inflammation of GB was presented that will limit mobilization and increased the surgical difficulty. With higher score or grading scale can predict longer operation time and more difficult LC which should be performed or supervised by senior operator in order to reach a safety operation.
\end{abstract}

\section{Keywords}

Laparoscopic cholecystectomy, Grading scale, Surgical difficulty, Cholecystitis

\section{Introduction}

Laparoscopic cholecystectomy (LC) has rapidly become a major selection and feasible procedures nowadays [1]. Sometimes, we will meet the difficulty at operation even done by well experienced surgeon. Various problems are considerateness in causing the surgical difficulty such as inflammatory severity of GB, peri-GB adhesions, scarring and resulted from identifying anatomy in difficulty of LC [2-4]. The majority of previous scoring methods were using a combination of pre-operative and operative data by retrospective data for analysis [5]. As a co-authors of previous multi-national survey by groups comprising LC surgeons in Japan, Korea, and Taiwan [4]. Most surgeons agreed that surgical difficulty increases in the case of high severity of fibrotic change and scarring development. Impact of intra-operative scenario will be as a decision key of surgical difficulty. Actually, risk factors for surgical difficulty might be affected by the skill of surgeon and hospital policy also.

Most of the evaluations grading scales were based on

*Corresponding author: Chen-Guo Ker, MD., M.Ph.D., FACS, Professor and Consultant Surgeon, Department of Digestive Surgery, Yuan's General Hospital, Cheng-Kung $1^{\text {st }} \mathrm{Rd}$. Kaohsiung 80249, Taiwan

Accepted: December 28, 2019

Published online: December 30, 2019

Citation: Chen-Guo K, Hong-Yi T, Ming-Yuen Y, et al. (2019) Study of Score System for Surgical Difficulty of Laparoscopic Cholecystectomy. Adv Laparoscopy 2(1):63-68 
Citation: Chen-Guo K, Hong-Yi T, Ming-Yuen Y, et al. (2019) Study of Score System for Surgical Difficulty of Laparoscopic Cholecystectomy. Adv Laparoscopy 2(1):63-68

Table 1: The surgical difficulty score of operative findings of Gall-bladder (GB), Calot's triangle, GB bed.

\begin{tabular}{|l|l|l|}
\hline Operative findings & Grade of inflammation (0-3) & Score \\
\hline Appearance of GB & 1. Adhesion: None to diffuse & $0-3$ \\
\hline & 2. Edema and necrosis: None to severe & $0-3$ \\
\hline Calot's triangle & 3. Contracted and fibrosis: None to severe & $0-3$ \\
\hline & 4. Edema: None to severe & $0-3$ \\
\hline 5. Fibrosis: None to severe & $0-3$ \\
\hline Gallbladder bed & 6. Scarring: None to severe & $0-3$ \\
\hline & 7. Edema and necrosis: None to severe & $0-3$ \\
\hline & 8. Fibrosis: None to severe & $0-3$ \\
\hline Additional difficulty & 9. Scarring: None to severe & $0-3$ \\
\hline & 10. Gangrene of GB & $0-3$ \\
\hline & 11. GB fistula & $0-3$ \\
\hline
\end{tabular}

SD-Grade 1: Score 0-3, easy procedure, SD-Grade 2: Score 4-12, moderate, SD-Grade 3: Score > 13, severe difficulty.

the anatomic findings and patient's data for grading. The definition of acute cholecystitis (AC), grading of $A C$, and grading of surgical difficulty were various in each institution. Grading of surgical difficulty will depend on one of the factors by the severity grading of AC. In Japan, Iwashita, et al. [6] led a studying group to hypothesize that objective findings during LC that directly correlate with inflammatory changes of the gallbladder are ideal indices to evaluate surgical difficulty in 2016 [4,6]. An inauguration of a Japan-Korea-Taiwan multinational collaborative project was raised and led to the evaluation 25 items. These 25 key items were objective intra-operative findings that contribute to surgical difficulty during LC. Expert surgeons from Japan-Korea-Taiwan participated in grading the 25 intra-operative findings using the seven scales ranging from 0 to 6 for evaluation of surgical difficulty and had been demonstrated to potentially contribute to surgical difficulty [4]. From this project, jointed surgeons had intended to establish a gold standard that could be universally adapted to grade surgical difficulty essentially novel.

Clinical use of pre-operative findings including appearance of gallbladder (GB), Calot's triangle, GB bed and additional conditions were invested in our patients who were diagnosed as acute cholecystitis and treated with LC. In addition to our scoring methods, there were other grading scale methods mentioned in the literatures $[5,7]$. In order to clarify and compare each grading scale for the surgical difficulty of LC, Our aims were to predict the surgical difficulty by cholecystectomy time and who can act as an operator for the patient where possible in our future. Therefore, we conducted this study to measure the laparoscopic cholecystectomy time and the risk factors based on scoring scale and make a comparison with others.

\section{Patients and Methods}

There were 793 LC for the patients of GB diseases totally from 2015 to 2016. Among them, 206 (25.9\%) patients were treated with a diagnosis of acute cholecystitis based on the criteria of Tokyo Guideline 2013 (TG13) [8]. These 206 patients were 89 of male, and 117 of female and their age ranged 23-85 year-old. Under the criteria of Tokyo Guideline 2013 (TG13) [8,9], assessment of severity of acute cholecystitis was classified as Grade I (mild), Grade II (moderate) and Grade III (severe). According to the criteria of TG13, the affecting factors were included the pre-operative clinical symptom/signs, laboratory data, and imaging findings (Echo, CT, or $\mathrm{MRI})$.

We designed this evaluation worksheet as Surgical Difficulty Scoring Scale which was modified from Iwashita Surgical Difficulty Scoring System in 2016 from Iwashita Y, et al. $[4,6]$. Based on the peri-operative findings of appearance of GB (0-3 score), Calot's triangle (0-3 score), GB bed (0-3 score) and additional 3 conditions (gangrene GB, GB fistule, and Mirizzi's symdrome, 0-3 score for each) were scored as Table 1. If adhesion, edema, fibrosis or scarring area is $<30 \%$ will termed mild, $31-60 \%$ termed moderate and $>61 \%$ termed severe. Score $=0$ means normal; score $=1,2$, and 3 for mild, moderated, and severe in degree respectively in each item. Concerning the cholecystectomy time was measured from the beginning with the laparoscopic instrument grasping GB to end of the GB separated and homeostasis completely through $L C$. The length of cholecystectomy time will reflect the surgical difficulty truly correlated with the score of peri-operative findings of $\mathrm{GB}$ alone prospectively.

Each variable enrolled in this study, $95 \% \mathrm{Cl}$ for pre-operative and peri-operative difficulty factors with uni- and multi-variate were analyzed. These results are presented as mean \pm sd. Statistical analysis were performed with an unpaired Student's t test, one-way ANOVA for more than two groups and linear regression analysis. The $P$ values less than 0.05 were considered to be significant.

\section{Results}

\section{Surgical score of each variable}

Surgical difficulty (SD) grading score was classified into 3 scales termed SD-Grade 1: Score 0-3, easy procedure, 
Citation: Chen-Guo K, Hong-Yi T, Ming-Yuen Y, et al. (2019) Study of Score System for Surgical Difficulty of Laparoscopic Cholecystectomy. Adv Laparoscopy 2(1):63-68

Table 2: Descriptive profile of patients divided into three grades according to cholecystectomy time.

\begin{tabular}{|c|c|c|c|c|c|c|c|c|}
\hline \multirow[b]{4}{*}{ Variables } & \multirow[b]{4}{*}{ stratification } & \multicolumn{7}{|l|}{ Total Score } \\
\hline & & \multicolumn{2}{|l|}{ SD Grade 1} & \multicolumn{2}{|l|}{ SD Grade 2} & \multicolumn{2}{|l|}{ SD Grade 3} & \multirow[b]{3}{*}{ P value } \\
\hline & & 0- 3 & & 4-12 & & $\geqq 13$ & & \\
\hline & & $N=92$ & & $N=78$ & & $N=36$ & & \\
\hline Age & $($ mean $\pm s d)$ & $49.5 \pm 13.3$ & & $53.9 \pm 13.8$ & & $59.5 \pm 14.3$ & & $0.001^{*}$ \\
\hline \multirow[t]{2}{*}{$\operatorname{Sex}(n, \%)$} & Male & 32 & 34.8 & 32 & 41 & 25 & 69.4 & $0.002^{*}$ \\
\hline & Female & 60 & 65.2 & 46 & 59 & 11 & 30.6 & \\
\hline \multirow[t]{3}{*}{ Cholecystitis Grade (n, \%) } & I: Mild & 71 & 80.7 & 27 & 36.5 & 3 & 8.3 & - \\
\hline & II: Moderate & 17 & 19.3 & 45 & 60.8 & 30 & 83.3 & \\
\hline & III: Severe & 0 & 0 & 2 & 2.7 & 3 & 8.3 & \\
\hline \multicolumn{9}{|l|}{ Score } \\
\hline 1.GB & $($ mean $\pm s d)$ & $0.4 \pm 0.6$ & & $2.4 \pm 1.3$ & & $5.8 \pm 2.1$ & & $<0.001^{*}$ \\
\hline 2.Calot's Triangle & $($ mean $\pm s d)$ & $0.4 \pm 0.5$ & & $2.5 \pm 1.2$ & & $6.3 \pm 1.7$ & & $<0.001^{*}$ \\
\hline 3.Liver Bed & $($ mean $\pm s d)$ & $0.3 \pm 0.5$ & & $2.1 \pm 1.1$ & & $5.6 \pm 1.7$ & & $<0.001^{*}$ \\
\hline \multirow[t]{2}{*}{ Op type $(n, \%)$} & Elective & 92 & 100 & 68 & 87.2 & 25 & 69.4 & $<0.001^{*}$ \\
\hline & Emergency & 0 & 0 & 10 & 12.8 & 11 & 30.6 & \\
\hline Cholecystectomy time (min.) & $($ mean $\pm s d)$ & $23.9 \pm 11.5$ & & $41.5 \pm 23.6$ & & $74.3 \pm 32.1$ & & $<0.001^{*}$ \\
\hline \multirow[t]{2}{*}{ Drainage $(n, \%)$} & No & 92 & 100 & 67 & 85.9 & 32 & 88.9 & $<0.001^{*}$ \\
\hline & Yes & 0 & 0 & 11 & 14.1 & 4 & 11.1 & \\
\hline \multirow[t]{2}{*}{ Bleeding (n, \%) } & $<100 \mathrm{ml}$ & 92 & 100 & 75 & 96.2 & 27 & 75 & - \\
\hline & $\geqq 100 \mathrm{ml}$ & 0 & 0 & 3 & 3.8 & 9 & 25 & \\
\hline
\end{tabular}

${ }^{*} \mathrm{p}<0.05$.

Table 3: Multivariate regression model for predictor of surgical difficulty of GB score.

\begin{tabular}{|c|c|c|c|c|c|}
\hline \multirow[b]{2}{*}{ Variables } & \multirow[b]{2}{*}{$\boldsymbol{\beta}$} & \multirow[b]{2}{*}{ SE } & \multicolumn{2}{|c|}{$95 \% \mathrm{Cl}$ of $\beta$} & \multirow[b]{2}{*}{$P$ value } \\
\hline & & & Lower & Upper & \\
\hline Age & 0 & 0.007 & -0.014 & 0.013 & 0.953 \\
\hline \multicolumn{6}{|l|}{ Sex } \\
\hline \multicolumn{6}{|l|}{ Male (Ref.) } \\
\hline Female & 0.144 & 0.185 & -0.22 & 0.509 & 0.436 \\
\hline \multicolumn{6}{|l|}{ Grade } \\
\hline \multicolumn{6}{|l|}{ Mild (Ref.) } \\
\hline Moderate & 0.425 & 0.249 & -0.065 & 0.916 & 0.089 \\
\hline Severe & -0.394 & 0.675 & -1.725 & 0.936 & 0.56 \\
\hline \multicolumn{6}{|l|}{ Op type } \\
\hline \multicolumn{6}{|c|}{ Elective (Ref.) } \\
\hline Emergency & 0.137 & 0.328 & -0.509 & 0.783 & 0.676 \\
\hline \multicolumn{6}{|l|}{ Total score } \\
\hline \multicolumn{6}{|c|}{0 to 3 (Ref.) } \\
\hline 4 to 12 & 1.777 & 0.238 & 1.309 & 2.246 & $<0.001^{*}$ \\
\hline$\geqq 13$ & 4.565 & 0.377 & 3.822 & 5.307 & $<0.001^{*}$ \\
\hline \multicolumn{6}{|l|}{ Drainage } \\
\hline \multicolumn{6}{|l|}{ No (Ref.) } \\
\hline Yes & 0.084 & 0.368 & -0.81 & 0.641 & 0.819 \\
\hline \multicolumn{6}{|l|}{ Bleeding } \\
\hline \multicolumn{6}{|c|}{$<100 \mathrm{ml}$ (Ref.) } \\
\hline$\geqq 100 \mathrm{ml}$ & 0.907 & 0.461 & -0.003 & 1.817 & 0.051 \\
\hline
\end{tabular}

Full model Adj- $R^{2}=0.718, F=35.75, p<0.001,{ }^{*} P<0.05$. 
Citation: Chen-Guo K, Hong-Yi T, Ming-Yuen Y, et al. (2019) Study of Score System for Surgical Difficulty of Laparoscopic Cholecystectomy. Adv Laparoscopy 2(1):63-68

SD-Grade 2: Score 4-12, moderate, and SD-Grade 3: Score $>13$, difficult in procedure. The cholecystectomy time was measured $23.9 \pm 11.5,41.5 \pm 23.6$ and $74.3 \pm 32.1 \mathrm{~min}$ for SD-Grade 1,2 , and 3 respectively with a significant difference $(p<0.001)$ as shown in Table 2 . The distributions of SD Grading 1, 2 and 3 were found in 92 (50\%), 78 (32.5\%), and $32(17.5 \%)$ patients respectively. The SD-Grade 3 was found that the majority was in elder age, male, and Grade II \& III of acute cholecystitis in our series. There was no patient of SD-Grade 3 in acute cholecystitis of Grade I and none in the patients treated by pre-operative biliary drainage.

\section{Multivariate analysis of surgical difficulty}

After our multiple regressions analysis for the predictor of surgical difficulty of LC showed that the SD Grade 2 and 3 had 1.77 and 4.5 times difficulty than that of SD Grade 1 as Table 3. Pre-operative drainage was needed in 15 patients, and 11 patients (73.3\%) termed as SD Grade 2 and cholecystectomy time will become easily around $60 \mathrm{~min}$. in our series.

\section{Discussion}

The treatment flowchart was followed the TG07 [9] or TG13 [8] for the diagnosis of acute cholecystitis in our series. A provisional outcome statement regarding the diagnostic criteria and criteria for severity assessment was discussed and finalized during an International Consensus Meeting held in Tokyo 2006. In case of the difficulty operation in acute cholecystitis Grade III, early or delay LC should be taken for consideration for the critical condition. LC is a common procedure by surgeons and the problem was how to let our patients to accept the different level of surgeons to get a surgical safety. We established a scoring system modified from Iwashita's 25 items [10]. In Japan,
Iwashita, et al. [6] led a studying group to hypothesize that objective findings during LC that directly correlate with inflammatory changes of the gallbladder are ideal indices to evaluate surgical difficulty in 2016 [4,6].

Either scoring system or grading system was used for scaling of the surgical difficulty. In addition to our score system, there were another two scoring method for surgical difficulty reported by Sugrue $[7,11]$ and Ibrahim [12] in UK and Ireland respectively in 2019. Actually, Sugrue scoring system proposed is based on the severity of cholecystitis and degree of potential difficulty with a score from 1 to 10 reported in Ireland in 2015 [7]. This scoring system had been adapted to use in Parkinstan for surgical difficulty of cholecystitis severity as well in 2018 [13]. The distributions of each grade after scoring were listed in the Table 4 and compared with others from the literatures [14-17]. New Sugrue Scoring System was taken under the leadership of the World Society of Emergency Surgery and reported G10 Scoring System by Sugrue in 2019 [11]. With this scoring system a score of $<2$ would be termed easy, 2 to 4 moderate, 5-7 very difficulty, and 8 to 10 , extreme difficulty as shown in Table 5 . The new G10 scoring system differed slightly from Sugrue's original published 10-point operative score with the addition of an extra category for the degree of GB adhesions (scoring 2 points). The previous ( 1 point) score for time to identify the cystic artery and duct was removed and replaced with a category which considered limited access due to adhesions from previous surgery. Overall, $112 / 504$ (22.2\%) patients were found to have a difficulty or extremely degree of operative difficulty as judged by a G-10 score of 5 or greater [11]. Their mean operation times were $71.8 \mathrm{~min}$ (range 15-400), and 87.3 min (range 24-278) for elective and emergency cases respectively $(p<0.0001)$. But in our series, cholecystectomy tome was longer in the SD Grade 3 and the emergency LC

Table 4: Distribution of scoring scale and grading scale of surgical difficulty (sd) for laparoscopic chlecystectomy for acute cholecystitis reported from the literatures.

\begin{tabular}{|c|c|c|c|c|c|}
\hline $\begin{array}{l}\text { SD Grade } \\
\text { Authors, Country Method, year } \\
\text { (ref) }\end{array}$ & $\begin{array}{l}\text { Grade } 1 \\
\text { easy } \\
\mathrm{N}(\%)\end{array}$ & $\begin{array}{l}\text { Grade } 2 \\
\text { mod. } \\
\mathbf{N}(\%)\end{array}$ & $\begin{array}{l}\text { Grade } 3 \\
\text { Difficulty } \\
\mathbf{N}(\%)\end{array}$ & $\begin{array}{l}\text { Grade } 4 \\
\text { very difficulty } \\
\mathrm{N}(\%)\end{array}$ & $\begin{array}{l}\text { Grade } 5 \\
\text { extremely Difficulty } \\
\mathrm{N}(\%)\end{array}$ \\
\hline $\begin{array}{l}\text { Griffiths EA, UK Nassar Scale, } 1995 \\
\text { [14] }\end{array}$ & $\begin{array}{l}1359 \\
(33.7 \%)\end{array}$ & $\begin{array}{l}1260 \\
(31.2 \%)\end{array}$ & $\begin{array}{l}802 \\
(19.9 \%)\end{array}$ & $\begin{array}{l}614 \\
(15.2 \%)^{*}\end{array}$ & $<1 \%^{*}$ \\
\hline $\begin{array}{l}\text { Hanna GB, UK Cuschieri Scale, } \\
1998 \text { [15] }\end{array}$ & $\begin{array}{l}24 \\
(40.0 \%)\end{array}$ & $\begin{array}{l}19 \\
(31.7 \%)\end{array}$ & $\begin{array}{l}17 \\
(28.3 \%)\end{array}$ & NA & NA \\
\hline $\begin{array}{l}\text { Ahmend N, Parkistan Sugrue } \\
\text { System, } 2018 \text { [13] }\end{array}$ & $\begin{array}{l}24 \\
(20 \%)\end{array}$ & $\begin{array}{l}59 \\
(49.2 \%)\end{array}$ & $\begin{array}{l}31 \\
(25.8 \%)\end{array}$ & $\begin{array}{l}6 \\
(5 \%)\end{array}$ & NA \\
\hline $\begin{array}{l}\text { Madni TD, USA AAST System, } \\
2018 \text { [16] }\end{array}$ & $\begin{array}{l}18 \\
(10.1 \%)\end{array}$ & $\begin{array}{l}59 \\
(33.0 \%)\end{array}$ & $\begin{array}{l}37 \\
(20.7 \%)\end{array}$ & $\begin{array}{l}37 \\
(20.7 \%)\end{array}$ & $\begin{array}{l}34 \\
(19.1 \%)\end{array}$ \\
\hline $\begin{array}{l}\text { Madni TD, USA Parkland Grading, } \\
2019 \text { [17] }\end{array}$ & $\begin{array}{l}69 \\
(21.8 \%)\end{array}$ & $\begin{array}{l}113 \\
(35.6 \%)\end{array}$ & $\begin{array}{l}61 \\
(19.2 \%)\end{array}$ & $\begin{array}{l}44 \\
(13.9 \%)\end{array}$ & $\begin{array}{l}30 \\
(9.5 \%)\end{array}$ \\
\hline $\begin{array}{l}\text { Present series, Taiwan Ker's SD } \\
\text { Grading Score }\end{array}$ & $\begin{array}{l}103 \\
(50.5 \%)\end{array}$ & $\begin{array}{l}67 \\
(32.5 \%)\end{array}$ & $\begin{array}{l}36 \\
(17.5 \%)\end{array}$ & NA & NA \\
\hline
\end{tabular}


Citation: Chen-Guo K, Hong-Yi T, Ming-Yuen Y, et al. (2019) Study of Score System for Surgical Difficulty of Laparoscopic Cholecystectomy. Adv Laparoscopy 2(1):63-68

Table 5: Sugrue G10 grading system severity (2019).

\begin{tabular}{|l|l|}
\hline Variable & point \\
\hline Gallbladder appearance & 3 (max) \\
\hline Adhesions < 50\% of GB & 1 \\
\hline Adhesion > 50\% of GB buried & 2 \\
\hline Adhesions burying GB & 3 (max) \\
\hline Distension or contraction & 3 (max) \\
\hline Distended GB (or contracted shrivelled GB) & 1 \\
\hline $\begin{array}{l}\text { Unable to grasp with atraumatic laparoscopic forceps } \\
\text { Stone } \geq 1 \text { cm impacted in Hartman's Pouch }\end{array}$ & 1 \\
\hline Access & 1 \\
\hline BMI > 30 & 2 (max) \\
Adhesions from previous surgery limiting access & 1 \\
\hline Sepsis or complications & 1 \\
\hline Free bile or Pus outside the GB & 2 (max) \\
Fistula & 1 \\
\hline Total max & 1 \\
\hline Degree of Difficulty: SD Grade 1 Mild & 10 \\
\hline $\begin{array}{l}\text { SD Grade 2 Moderate } \\
\text { SD Grade 3 Severe } \\
\text { SD Grade 4 Extremely }\end{array}$ & $<2$ \\
\hline
\end{tabular}

has a 0.137 time difficulty compared with elective LC without significant difference.

Another one, Ibrahim Pre-operative Difficulty Score was reported in UK in 2019 [12] using the worksheet template devised by the American college of Surgeons (ACS) for its National Service Quality Improvement Program (NSQIP). In order to understand pre-operative difficulty is essential in predicting those who may need conversion to open surgery, selecting appropriate cases for trainees based on grade, and concerning patient outcomes and safety. Finally, four pre-operative variables had been identified and predicted a longer duration of surgery and presumed to reflect a more difficult procedure in Table 6 . In this score system, higher BMI has been suggested to cause difficulty due to troublesome manipulation of surgical instruments and excessive intra-peritoneal fat making optimal access more difficult. According to suggestions from the Ibrahim Pre-operative Difficulty Score [12], total score was subsequently divided into three groups formulating three categories and patients of Grade 1 (done by general surgeon) for a score of 1-4, Grade 2 (done by upper gastrointestinal surgeon) for a score of 5-8 and Grade 3 (done by hepato-biliary surgical specialist) for any score more than score 8 as shown in Table 6.

Grading the surgical difficulty could provide information for surgeons who have to challenge the surgical difficulty. Although the disaster of LC was rare, complication will be severe if happened. Grading scales of surgical difficulty were reported a little and all are not complete compatible. Most surgeons of LC will usually pay more attention to the scenario of surgical field and even the scenario was classified as a low
Table 6: Ibrahim pre-operative difficulty score of LC (2019).

\begin{tabular}{|l|l|l|}
\hline \multirow{4}{*}{ Variable } & \multicolumn{1}{|l|}{ Score } \\
\hline \multirow{3}{*}{ Age } & Female & 0 \\
\hline \multirow{3}{*}{ Previous ERCP } & Male & 2 \\
\hline \multirow{5}{*}{ BMI } & $<49 \mathrm{yr}$ & 0 \\
\hline & $>49 \mathrm{yr}$ & 2 \\
\hline \multirow{3}{*}{ Scoring Classification } & No & 0 \\
\hline \multirow{2}{*}{ Yes } & 2 \\
\hline & $18.50-24.99$ & 1 \\
\hline & $25-29.99$ & 4 \\
\hline & $>30$ & 5 \\
\hline & SD Grade 1 & $1-4$ \\
\hline & SD Grade 2 & $5-8$ \\
\hline & SD Grade 3 & $>8$ \\
\hline
\end{tabular}

grade of severity in order to avoid bilio-vascular injury during LC. The grading of surgical difficulty was high before operation and surgeons would be more allergic. Without question, surgical major complication could be happened in any grade of inflammation or difficulty. However, the surgical difficulty was grading by the score of each variable or grading of inflamed GB. Both were available for deciding the surgical difficulty. But the grading of acute cholecystitis sometimes was depended on the total results getting together including the patient's data, imaging study, operation findings and pathological findings [18].

In addition to the score system, grading scale system was also mentioned such as Nassar Surgical Difficulty Grading Scale [10]. This grading system was designed to be used as overall brief results of the operative findings and defined Grade 1, 2, 3 and 4 based on the operative difficulty scales in UK. But the worst factor found in the individual aspect of either the gallbladder, cystic pedicle or adhesions should be used to define the final overall grade. Although this scale was modified in 1996 in the cohort to include a Grade 5 which was defined as the presence of either Mirizzi type 2 or higher, cholecysto-cutaneous, cholecysto-duodenal or cholecysto-colic fistula. However, only less than $1 \%$ of the patients had a Grade 5 operative difficulty as shown in Table 4. In 1998 Cuschieri Scale System [11] for surgical difficulty of each LC was graded. Surgical difficulty of these patients were 24 (40.0\%), 19 (31.7\%), and $17(28.3 \%)$ classified in to Grade 1, 2, and 3 respectively as shown in Table 4. In USA, American Association for the Surgery of Trauma (AAST) project has an aim to develop a uniform grading system for measuring anatomic severity of disease in Emergency General Surgery (EGS) patients called AAST EGS grade of acute cholecystitis severity in 2014 [19]. They describe the proposed grading system and a simple description of disease grade should be included in the emerging EGS registries. EGS patients were recorded by using the findings derived from 3 categories: i) clinical, ii) imaging, iii) operative, reported in 2014 [19]. In 2016, more detail descriptions and grade was including the pathologic findings in addition to the previous 3 cate- 
gories [20]. Level of operator of LC should depend on the patient's cholecystitis grading and difficulty at the time of emergency service being a policy for practice.

In conclusion, either score system or grading scale system was approved to provide a police of surgical treatment of LC for GB diseases. If higher score or grading scale was present in a patient who will increase the surgical difficulty and longer cholecystectomy time. In order to improve surgical safety our scoring scale can be used to predict who can act as an operator or need a supervisor where possible. However, more prospective validation will be needed for further study.

\section{Conflicts of Interest}

There are no any of conflicts of interest from this manuscript or institution or method that is mentioned in the manuscript.

\section{Contribution of Authors}

\section{Study design}

Chen-Guo Ker.

\section{Data collection}

Hong-Yi Tong, Ming-Yuen Yang, I-Tsou Tseng, Der-Ming Chang, Kuo-Chen Hung, Hong-Yaw Chen.

\section{Data collection and analysis}

Hong-Yi Tong, Yu-Fu Chen.

\section{Interpretation and manuscript}

Chen-Guo Ker.

\section{References}

1. Z'Graggen K, Metzger A, Birrer S, et al. (1995) Laparoscopic cholecystectomy as standard therapy in acute cholecystitis. A prospective study. Chirurg 66: 366-370.

2. Ashfaq A, Ahmadieh K, Shah AA, et al. (2016) The difficult gall bladder: Outcomes following laparoscopic cholecystectomy and the need for open conversion. Am J Surg 212: 1261-1264.

3. Beksac K, Turhan N, Karaagaoglu E, et al. (2016) Risk factors for conversion of laparoscopic cholecystectomy to open surgery: $A$ new predictive statistical model. J Laparoendosc Adv Surg Tech A 26: 693-696.

4. Iwashita Y, Hibi T, Ohyama T, et al. (2017) An opportunity in difficulty: Japan-Korea-Taiwan expert Delphi consensus on surgical difficulty during laparoscopic cholecystectomy. J Hepatobiliary Pancreat Sci 24: 191-198.

5. Griffiths EA, Hodson J, Vohra RS, et al. (2019) Utilisation of an operative difficulty grading scale for laparoscopic cholecystectomy. Surg Endosc 33: 110-121.
6. Iwashita Y, Ohyama T, Honda G, et al. (2016) What are the appropriate indicators of surgical difficulty during laparoscopic cholecystectomy? Results from a Japan-Korea-Taiwan multinational survey. J Hepatobiliary Pancreat Sci 23: 533-547.

7. Sugrue M, Sahebally SM, Ansaloni L, et al. (2015) Grading operative findings at laparoscopic cholecystectomy- a new scoring system. World J Emerg Surg 10: 14.

8. Yokoe M, Takada T, Strasberg SM, et al. (2013) TG13 diagnostic criteria and severity grading of acute cholecystitis (with videos). J Hepatobiliary Pancreat Sci 20: 35-46.

9. Hirota M, Takada T, Kawarada Y, et al. (2007) Diagnostic criteria and severity assessment of acute cholecystitis: Tokyo guidelines. J Hepatobiliary Pancreat Surg 14: 78-82.

10. Iwashita Y, Hibi T, Ohyama T, et al. (2017) Delphi consensus on bile duct injuries during laparoscopic cholecystectomy: An evolutionary cul-de-sac or the birth pangs of a new technical framework? J Hepatobiliary Pancreat Sci 24: 591-602.

11. Sugrue $M$, Coccolini F, Bucholc $M$, et al. (2019) Intra-operative gallbladder scoring predicts conversion of laparoscopic to open cholecystectomy: A WSES prospective collaborative study. World J Emerg Surg 14: 12.

12. Ibrahim Y, Radwan RW, Abdullah AAN, et al. (2019) A retrospective and prospective study to develop a pre-operative difficulty score for laparoscopic cholecystectomy. J Gastrointest Surg 23: 690-695.

13. Ahmed N, Hassan MU, Tahira M, et al. (2018) Intra-operative predictors of difficult cholecystectomy and conversion to open cholecystectomy - a new scoring system. Pak J Med Sci 34: 62-66.

14. Nassar A, Ashkar K, Mohamed A, et al. (1995) Is laparoscopic cholecystectomy possible without video technology? Minim Invasive Ther Appli Technol 4: 63-65.

15. Hanna GB, Shimi SM, Cuschieri A, et al. (1998) Randomised study of influence of two-dimensional versus three-dimensional imaging on performance of laparoscopic cholecystectomy. Lancet 351: $248-251$.

16. Madni TD, Leshikar DE, Minshall CT, et al. (2018) The Parkland grading scale for cholecystitis. Am J Surg 215: 625-630.

17. Madni TD, Nakonezny PA, Barrios E, et al. (2019) Prospective validation of the Parkland Grading Scale for Cholecystitis. Am J Surg 217: 90-97.

18. Madni TD, Nakonezny PA, Imran JB, et al. (2019) A comparison of cholecystitis grading scales. J Trauma Acute Care Surg 86: 471478.

19. Shafi S, Aboutanos M, Brown CV, et al. (2014) Measuring anatomic severity of disease in emergency general surgery. J Trauma Acute Care Surg 76: 884-887.

20. Tominaga GT, Staudenmayer KL, Shafi S, et al. (2016) The American Association for the Surgery of Trauma grading scale for 16 emergency general surgery conditions: Disease-specific criteria characterizing anatomic severity grading. J Trauma Acute Care Surg 81: 593-602.

DOI: $10.36959 / 367 / 443$

Copyright: (C) 2019 Chen-Guo K, et al. This is an open-access article distributed under the terms of the Creative Commons Attribution License, which permits unrestricted use, distribution, and reproduction in any medium, provided the original author and source are credited. 